Jurnal IImiah Iqra'

2541-2108 [Online] 1693-5705 [Print]

Tersedia online di: http://journal.iain-manado.ac.id/index.php/JII

\title{
Dampak Pengembangan Karir terhadap Kinerja Karyawan Pendidikan Tinggi Islam
}

\author{
Shinta Nento \\ Institut Agama Islam Negeri, Manado, Indonesia \\ shintanento@iain-manado.ac.id
}

\author{
Abdul Haris Abdullah \\ Institut Agama Islam Negeri Sultan Amai, Gorontalo, Indonesia \\ abdulharisabdullah1976@iaingorontalo.ac.id
}

\begin{abstract}
Abstrak
Penelitian ini merupakan penelitian kuantitatif dengan menggunakan data primer yang diperoleh dari angket dan diukur dengan menggunakan skala likert. Populasi dalam penelitian ini adalah karyawan di lembaga pendidikan tinggi islam sebanyak 75 orang. Metode pemilihan sampel penelitian menggunakan simple random sampling acak tanpa memperhatikan strata anggota populasi karena dianggap telah homogen. Teknik analisis data pengukuran dan pengujian yang digunakan dalam penelitian adalah Structural Equation Modeling (SEM) berbasis Partial Least Square (PLS) dengan menggunakan program SmartPLS 3.2. Hasil penelitian menunjukkan bahwa pengembangan karir berpengaruh positif dan signifikan terhadap kinerja pegawai. Rekomendasi bagi penelitian lanjutan adalah menambah jumlah variabel penelitian dan menggunakan mix method sebagai metode untuk memperkaya telaah.
\end{abstract}

Kata kunci: Pengembangan karir; kinerja karyawan; pendidikan tinggi islam

\begin{abstract}
Impact of career development on employee performance of Islamic higher education. This research is a quantitative study using primary data obtained from a questionnaire and measured using a Likert scale. The population in this study were 75 employees at Islamic higher education institutions. The method of selecting the research sample used simple random sampling without considering the strata of the members of the population because it was considered homogeneous. The measurement and testing data analysis technique used in this research is Structural Equation Modeling (SEM) based on Partial Least Square (PLS) using the SmartPLS 3.2 program. The results showed that career development had a positive and significant effect on employee performance. Recommendations for further research are to increase the number of research variables and use the mix method as a method to enrich the study.
\end{abstract}

Keywords: career development; employee performance; Islamic higher education 


\section{Pendahuluan}

Keberadaan karyawan merupakan bagian integral dalam kehidupan organisasi pendidikan(Arsi \& Arsyam, 2021). Karena karyawan mempunyai peranan strategis dalam lingkup pendidikan maka pembinaan personil yang ada menjadi tanggungjawab pimpinan tertinggi dalam lingkup organisasi(Kennington, 2020). Karenanya pimpinan pada institusi pendidikan dimaksud mempunyai keharusan memahami lingkup dimensi pengelolaan sumberdaya manusia yang dipimpinya(Farikhah, 2015); dan (Soomro et al., 2020). Banyak masalah yang tidak terpisahkan dari kehidupan lingkungan pendidikan tinggi sebagai suatu organisasi(Jandrić et al., 2020). Masalah-masalah ini mencakup beberapa aspek, seperti merumuskan visi, mendefinisikan tujuan, menentukan kebijaksanaan, mengembangkan program, mempekerjakan karyawan, mengadakan fasilitas atau sarana prasarana pendidikan, pengembangan karir karyawan, pencapaian hasil dan mengkoordinasikan kegiatan-kegiatan yang terpisah-pisah(Ahmad, 2020). Semuanya memerlukan keterlibatan orang-orang dengan latar belakang keilmuan dan kemampuan yang berbeda-beda, seperti penyediaan karyawan profesional, personil administrasi, pustakawan, laboran, cleaning service, pengelolah taman sekolah, dan sebagainya(Yasin, 2011). Usaha menghadirkan karyawan yang dapat diandalkan bekerja professional dalam lingkungan pendidikan tinggi membutuhkan upaya yang direncanakan melalui pengembangan sumberdaya manusia(Armstrong \& Taylor, 2020). Praktek pengembangan sumberdaya manusia atau karyawan telah didefinisikan sebagai serangkaian aktivitas, fungsi, dan proses yang berbeda namun saling terkait yang diarahkan pada, mengembangkan, dan memelihara sumber daya manusia dalam organisasi(Stahl et al., 2020). Praktek sumberdaya di banyak organisasi sebagian besar terlibat dalam operasi, sistem dan masalah pengaturan kompensasi, pengembangan individu dan perekrutan(Heilmann et al., 2020). Ketika praktek sumberdaya manusia mengadopsi peran strategis, maka akan menghasilkan kinerja tinggi dalam waktu relative singkat(Alfes et al., 2020). Investasi dalam sumberdaya manusia yang diadopsi oleh organisasi akan berkontribusi menciptakan sumber daya manusia organisasi tertentu dan akan berkontribusi untuk meningkatkan pengetahuan, keterampilan, dan kemampuan karyawan, mengurangi jumlah yang keluar dari organisasi, dan meningkatkan motivasi mereka untuk bekerja(Yusliza et al., 2020). Selain itu pengembangan sumberdaya manusia yang bertujuan untuk mengembangkan kemampuan, peluang, motivasi dan keseimbangan karyawan antara kehidupan dan pekerjaan mereka dianggap efektif dan diterima oleh karyawan lain dan organisasi(Zhang et al., 2020).

(Aburumman et al., 2020) menyajikan banyak indikator dan dimensi pengembangan sumberdaya manusia, yang dapat digunakan sebagai daftar untuk mengevaluasi efektivitas pengembangan sumberdaya manusia. Studi ini akan fokus pada dimensi pengembangan karir. Meskipun demikian dimensi dan indikator dari pengembangan karir akan disebut dalam uraian kajian teori. Secara luas bahwa 
pengembangan karir sumberdaya manusia atau karyawan memiliki kemungkinan memotivasi karyawan dan membantu mencegah karyawan meninggalkan pekerjaan mereka, meningkatkan kinerja mereka(Dobre, 2013).

Kinerja sebagai catatan hasil dalam jangka waktu tertentu. Kinerja tergantung pada beberapa kombinasi kemampuan, motivasi dan situasional(Sudiardhita et al., 2019). (Bafadal et al., 2020) dan (Idris, 2019) mendefinisikan kinerja adalah evaluasi dari hasil perilaku seseorang. Hal ini berhubungan dengan tingkat penyelesaian pekerjaan yang diberikan organisasi. Pendapat lainnya (Han et al., 2020) kinerja adalah hasil dari pekerjaan yang terkait dengan organisasi, efisiensi dan keefektifan hasil kerja. Secara umum dalam mengukur kinerja, yang digunakan oleh para ahli di antaranya adalah kualitas pekerjaan, kuantitas pekerjaan, pengetahuan, kreativitas, efektivitas interpersonal, kerjasama, ketergantungan, inisiatif, personal, dan kemampuan beradaptasi(Matraeva et al., 2020). Menurut (Roszkowska \& Melé, 2020);(Javaid et al., 2020) dan (Prasad et al., 2020) tiga faktor yang mempengaruhi kinerja: Faktor individu, adalah kemampuan, keterampilan, latar belakang keluarga, pengalaman kerja, tingkat sosial dan demografi seseorang. Faktor psikologis, adalah persepsi, peran, sikap, kepribadian, motivasi dan kepuasan kerja. Faktor organisasi, budaya, lingkungan, iklim, jenis pekerjaan.

Berdasarkan pada uraian para ahli di atas, maka naskah ini selanjutnya akan menelusuri secara teoritik, pertama tentang pengembangan, penilaian, dan rencana pengembangan karir karyawan berkelanjutan. Kedua, mengidentifikasi teori-teori kinerja, dimensi dan indikator kinerja karyawan. Sementara tujuan secara spesifik penelitian ini adalah menjawab masalah dan sekaligus menguji pernyataan hipotesis penelitian bahwa terdapat dampak pengembangan karir terhadap kinerja karyawan di lingkungan pendidikan tinggi Islam.

\section{Kajian Teori}

\section{Pengembangan karir}

Dunia pasar kerja terjadi persaingan tingkat pendidikan, pengetahuan, keterampilan, dan kemampuan yang ditawarkan ke tempat kerja(Pan et al., 2020). Menurut (Panagiotakopoulos, 2020) setiap orang yang memiliki pendidikan dan lebih terlatih mampu menyediakan lebih banyak usaha produktif daripada orang dengan pendidikan dan pelatihan yang lebih rendah. Human capital theory diterima secara luas untuk meningkatkan kinerja organisasi, sehingga organisasi mengandalkan keterampilan, pengetahuan, kemampuan karyawan sebagai salah satu kunci penciptaan nilai(Hutahayan, 2020).

Pada abad kedelapan belas Adam Smith memprakarsai peningkatan kapabilitas manusia yang penting bagi produksi(Wyatt-Elkins, 2020). Theory human capital menyatakan bahwa tingkat pendidikan dan pelatihan yang berbeda 
berkontribusi pada tingkat upah dan gaji yang berbeda(Mellander \& Florida, 2021), semakin banyak pengetahuan, keterampilan dan kemampuan, semakin besar kemungkinan untuk mendapatkan yang lebih baik pekerjaan(Swanson et al., 2020). Kemudian (Washington, 2020) mengemukakan bahwa komponen human capital terdiri dari ability, knowledge, skill, personal talent, behaviour, dan effort. Komponen pengetahuan meliputi IQ, EQ, pengetahuan khusus dan umum untuk bekerja. Komponen keterampilan adalah keahlian yang digunakan dalam bekerja, termasuk tubuh fisik, dan pergerakan dalam pekerjaan. Komponen bakat adalah karakteristik pribadi yang bersifat bawaan dan dapat ditingkatkan dengan pengembangan(Leikin, 2020).

Organisasi yang berinvestasi pada human capital memandang manusia sebagai aset yang telah diinvestasikan dan diharapkan akan kembali dan memberikan nilai positif di masa depan. Dengan kata lain, investasi manusia melalui pendikan atau pelatihan akan meningkatkan kemajuan karir mereka. (Karman, 2020) berpendapat bahwa sumber daya manusia dipandang mengarah pada sumber nilai. Meskipun demikian, (Espino-Díaz et al., 2020) mengatakan bahwa telah terjadi pergeseran paradigma yang luar biasa dalam konsep human capital. Pergeseran ini mengubah fungsi sumber daya manusia dengan berpindah dari proses berbasis aktivitas ke berbasis hasil(Çelik, 2018). Selanjutnya (Abdurakhmanova et al., 2020) mengemukakan bahwa konsep human capital karyawan dipandang sebagai aset yang harus dikembangkan, dan diintegrasikan dengan teknologi.

\section{Mengukur Sumber Daya Manusia}

Pengukuran sumber daya manusia menurut (Otoo, 2019) menjadi penting untuk mengetahui dampak investasi sumber daya manusia dilakukan organisasi, yang selanjutnya akan dilakukan perbaikan jika terdapat kekurangan. (Dhamija et al., 2019) berpendapat bahwa pimpinan organisasi mengukur investasi sumberdaya manusia dengan menggunakan ukuran pendapatan, produktivitas, kepuasan pelanggan, keterlambatan dan ketidakhadiran.

(Leitão et al., 2019) mengatakan bahwa untuk mengukur human capital, organisasi perlu mengukur sikap dan perilaku karyawan serta kinerja internal dan eksternal seperti produktivitas dan kualitas produk dan jasa, serta hasil pekerjaan. Lebih lanjut (Nourani et al., 2018) mengusulkan metode pengukuran human capital dengan menggunakan jumlah karyawan, omset, dan promosi, keuangan, pemasaran, kendali mutu. Meskipun tidak ada konsensus untuk mengukur Human Capital, namun human capital umumnya diukur keuntungan organisasi dalam rentang waktu tertentu, komitmen organisasi, kepuasan pelanggan, pendapatan, dan kinerja keuangan organisasi. 


\section{Pengembangan Sumberdaya Manusia}

Sumber daya manusia dipandang sebagai sumber nilai dalam organisasi yang efektif sehingga dapat dikatakan terdapat hubungan signifikan antara teori modal manusia dengan bidang pengembangan sumber daya manusia(Kucharčíková \& Mičiak, 2018). Selain itu, sumberdaya manusia melibatkan pelatihan dan pengembangan karyawan yang terkait dengan bidang lain. Menurut (Fahim, 2018) dalam pengembangan sumberdaya manusia, kompensasi dan tunjangan, rekrutmen, analisis pekerjaan, rotasi pekerjaan, manajemen partisipatif, hubungan kerja serta manajemen kesejahteraan dan kinerja sebagai variabel yang perlu dipertimbangkan.

Teori human capital telah dianggap sebagai salah satu teori ekonomi karena peningkatan kinerja terjadi pada organisasi yang berbasis ekonomi, karena teori dan metode manajemen dipandang sebagai turunan berguna dalam teori ekonomi. (Faggian et al., 2019). Dalam rangka bertahan dalam ekonomi berbasis pengetahuan yang kompetitif serta menjaga keberlanjutan maka sumber daya manusia sebagai teori ekonomi perlu mendapatkan perhatian serius. Human capital theory dapat meningkatkan kinerja organisasi di pandangan oleh para ahli sebagai proses untuk jangka panjang dengan berfokus pada usaha memiliki potensi manusia berupa pengetahuan, keahlian, produktivitas(Jafari-Sadeghi et al., 2019).

\section{Kinerja karyawan}

Kinerja adalah perilaku yang ditampilkan sebagai prestasi kerja karyawan(Günay, 2018). Menurut (Sapada et al., 2018) kinerja merupakan hasil kerja yang dicapai oleh setiap orang atau sekelompok orang dalam organisasi.

Menurut (Esthi \& Savhira, 2019) definisi yang mirip dikatakan bahwa kinerja adalah hasil kerja yang dicapai seseorang dalam melaksanakan tugas-tugas yang dibebankan kepadanya. Menurut (Bryson, 2018) kinerja digambarkan sebagai tingkat pencapaian pelaksanaan atau program kegiatan atau kebijakan dalam mewujudkan sasaran, tujuan, visi dan misi organisasi serta strategis organasi. Sedangkan menurut (Polychroniou \& Trivellas, 2018) kinerja merupakan seperangkat hasil capaian tindakan yang dibebankan organisasi kepada seseorang.

Istilah kinerja merujuk pada kualitas dan kuantitas hasil capaian karyawan(Ogbonnaya \& Valizade, 2018). Selanjutnya, kinerja merupakan pekerjaan dalam periode tertentu(Alessandri et al., 2018). Kinerja sesorang diharapkan berfungsi secara sempurna dalam jenis pekerjaan yang diberikan organisasi(Leitão et al., 2019). Pendapat lain menjelaskan bahwa kinerja merupakan tingkat perbandingan antara keluaran dengan masukan dilihat dari capaian pekerjaan yang diberikan sekaligus merupakan efesiensi pengelolaan masukan dan efektivitas pencapaian(Salama et al., 2018). Kinerja dipengaruhi oleh tiga faktor yaitu: faktor individu, faktor psikologi dan faktor organisasi(Ahmed et al., 2018). Sedangkan 
untuk mengukur kinerja menurut (Liu et al., 2018) dapat di gunakan beberapa indikator seperti kualitas, kuantitas, ketepatan waktu, efektivitas biaya.

\section{Metode}

Studi ini menggunakan metode survei pendekatan kuantitatif. Penelitian survei ini menjelaskan hubungan kausal dan pengujian hipotesis serta memprediksi atau meramalkan kejadian (Riduwan \& Engkos Ahmad Kuncoro, 2007).

Pengukuran dan pengujian penelitian menggunakan bantuan software SmartPLS 3.2, yang terdiri dari dua sub model yaitu measurement model atau outer model dan structural model atau inner model(Ghozali, 2015).

Populasi penelitian adalah seluruh karyawan yang bekerja di IAIN Manado. Teknik yang digunakan dalam penarikan sampel dengan teknis simple random sampling tanpa memperhatikan strata anggota populasi karena dianggap telah homogen.

Teknik pengumpulan data dengan angket. Angket atau instrumen penelitian berasal dari penjabaran variabel pengembangan karir dan kinerja karyawan. Masingmasing instrumen dari setiap variabel di atas dilakukan validitas logis dan konstruk. Validitas logis untuk memastikan instrumen yang digunakan andal, sementara validitas konstruk dengan uji butir melalui software SPSS. Adapun reliabilitas instrumen untuk memastikan bahwa instrumen selalu stabil digunakan berulang dan konsisten dalam menjaring data. Skala yang digunakan adalah skala likert yakni pilihan paling rendah sampai pilihan paling tinggi dengan skala $1-5$. Kisi-kisi instrument penelitian sebagaimana tabel berikut:

Tabel 1 Variabel dan Indikator Penelitian

\begin{tabular}{lll}
\hline $\begin{array}{l}\text { Variabel } \\
\text { Pengembangan } \\
\text { Karir }\end{array}$ & Indikator & Deskriptor \\
\hline & Kengetahuan & $\begin{array}{l}\text { IQ \& EQ, Wawasan, berpikiran } \\
\text { terbuka, update informasi }\end{array}$ \\
\hline & Kemampuan & Mahir, melek teknologi, cekatan \\
\hline & Produktivitas & $\begin{array}{l}\text { Kerja tim, penguasan tugas, bekerja } \\
\text { di bawah tekanan }\end{array}$ \\
\hline Kinerja Karyawan & Disiplin tugas, hasil kerja, kualitas \\
\hline & Kualitas pekerjaan & Memuaskan, menarik, disukai \\
\hline & Kuantitas pekerjaan & Jumlah, ukuran \\
\hline & Kasil kerja & Tepat waktu, tepat sasaran \\
\hline & Komitmen organisasi & Menyenangkan, persepsi, sukses \\
\hline
\end{tabular}


Teknik analisis data menggunakan bantuan software pengolah data yakni software excel for windows untuk tabulasi data dan SmartPLS 3.2 untuk evaluasi sekaligus pengujian model penelitian. Analisis data penelitian dilakukan analisis model pengukuran beserta hasil model struktural.

Angket diedarkan kepada 100 responden target berbentuk angket (pertanyaan terstruktur dan tertutup). Angket kembali berjumlah 75 angket. Jumlah angket kembali masih memenuhi rasio sebagaimana idealnya sampel yang diprasyaratkan alat analisis statistik yakni SmartPLS 3.2. Adapun paradigma penelitian sebagaimana gambar berikut:

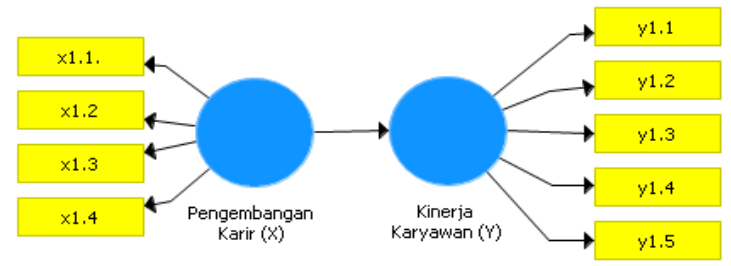

\section{Gambar 1. Paradigma Penelitian}

\section{Hasil}

\section{Evaluasi Outer Model}

Dalam model SmartPLS 3.2, convergent validity dikatakan valid jika nilai loading di atas 0.5 , yakni untuk menjelaskan kemampuan indikator menggambarkan konstruknya. Table berikut menampilkan nilai convergent validty dalam penelitian ini.

Tabel 1. Convergent Validity

\begin{tabular}{llc}
\hline Variabel & Indikator & Outer Loading \\
\hline Pengembangan Karir & Pengetahuan & 0.706 \\
\hline & Keterampilan & 0.695 \\
\hline & Kemampuan & 0.745 \\
\hline & Produktivitas & 0.634 \\
\hline Kinerja Karyawan & Kualitas pekerjaan & 0.626 \\
\hline & Kuantitas pekerjaan & 0.761 \\
\hline & Hasil kerja & 0.640 \\
\hline & Kepuasan kerja & 0.712 \\
\hline & Komitmen organisasi & 0.715 \\
\hline
\end{tabular}

Di samping uji validitas konstruk, dilakukan juga uji reliabilitas konstruk dengan maksud mengukur internal konsistensi dengan ketentuan bahwa nilai composite reliability adalah di atas 0.7 . Berikut ini nilai composite reliability hasil pengujian. 
Tabel 2. Composite Reliability

\begin{tabular}{lc}
\hline Variabel & Composite Reliability \\
\hline Pengembangan karir & 0.790 \\
\hline Kinerja karyawan & 0.821 \\
\hline
\end{tabular}

Berdasarkan tabel 2 di atas bahwa nilai composite reliability baik konstruk locus of control, kepuasan kerja dan komitmen organisasi semuanya di atas 0.7. Maka dapat disimpulkan bahwa keseluruhan konstruk memiliki reliabilitas memadai.

\section{Evaluasi Inner Model dan Outer Model}

Uji model dilakukan untuk mengevaluasi kontribusi antar konstruk seperti yang telah dihipotesiskan. Hasil uji model dapat dilihat pada gambar berikut:

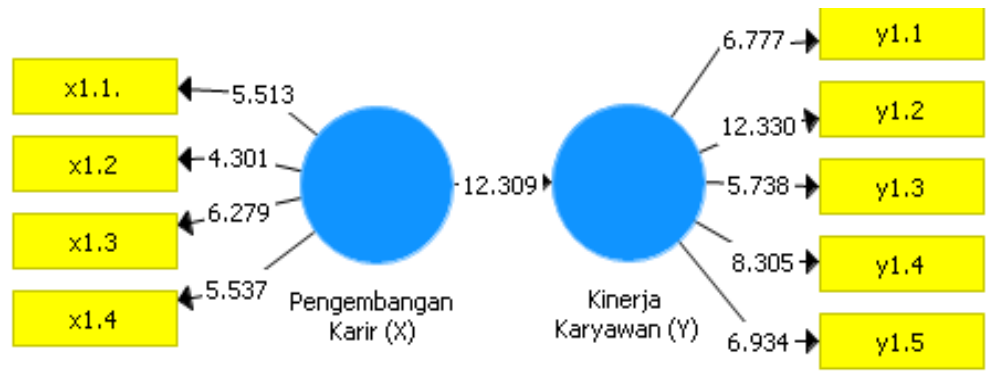

Gambar 2. Hasil pengujian model penelitian output bootstrapping

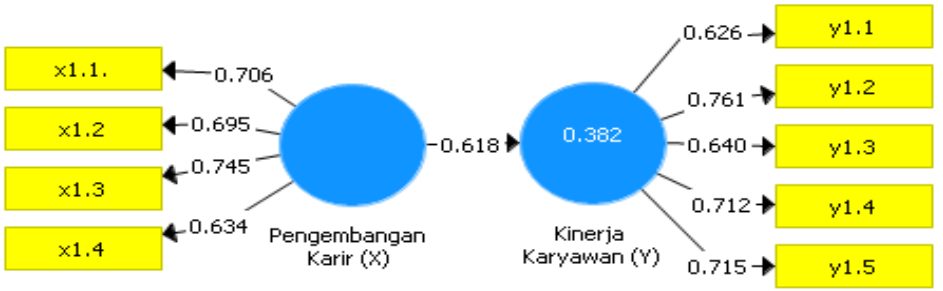

\section{Gambar 3. Hasil pengujian model penelitian output algoritma}

Asumsi pengujian model penerimaan ataupun penolakan didasarkan pada nilai $t_{\text {statistik }}$ dan P-Values. Jika $t_{\text {statistik }}>$ dari $t$-tabel $=1.666$ dan P-Values $<\alpha=0.10$, maka Ha diterima dan Ho ditolak. Demikian pula sebaliknya jika $t_{\text {statistik }}<$ dari $t$-tabel $=1.666$ dan P-Values $>a=0.10$, maka Ha ditolak dan Ho diterima.

Berdasar pada gambar pengujian model di atas, maka nilai $t_{\text {statistik }}>$ dari $t_{\text {-tabel }}$ = 12.309 sebagaimana yang tampak dalam gambar 2 di atas. Sedangkan nilai PValues $<$ a 0.10 yakni $=0.000$., maka dengan demikian asumsinya Ha diterima dan Ho ditolak. Artinya hasil pengujian ini menjelaskan bahwa pengembangan karir memiliki dampak terhadap kinerja karyawan di lingkungan pendidikan tinggi Islam. Nilai dampak dimaksud sebagaimana yang tampak dalam gambar 3 di atas yakni sebesar 0.618 atau $61.8 \%$. 


\section{Pembahasan}

Hasil temuan penelitian ini sejalan dengan beberapa penelitian sebelumnya pertama, sebuah penelitian yang mengajukan hipotesis menemukan bahwa pengembangan karir berpengaruh positif dan signifikan berdampak pada kinerja karyawan. Artinya semakin tinggi pengembangan karir maka semakin tinggi kinerja karyawan dan jika semakin rendah pengembangan karir, semakin rendah karyawan tersebut kinerja(Manggis et al., 2018). Temuan ini makin memperjelas bahwa pengembangan sumberdaya manusia pada dasarnya adalah berkaitan dengan upaya untuk merekrut, menyeleksi, menempatkan, melatih dan mengembangkan dan memanfaatkan mereka sesuai dengan kebutuhan yang diperlukan. Dalam konteks ini pengembangan dan pemanfaatan sumberdaya manusia memiliki peran strategis membentuk citra dan persepsi masyarakat terhadap lembaga-lembaga pendidikan Islam. Rekrutment, seleksi, penempatan, pelatihan, pengembangan dan pemanfaatan sumberdaya manusia membutuhkan peran kepemimpinan dalam setiap lembaga pendidikan Islam. Peranan kepemimpinan teramat penting sebagai pioner dalam menunjukkan komitmen pengembangan sumberdaya manusia (Yasin, 2011).

Temuan penelitian lainnya menyatakan bahwa setiap karyawan yang bekerja di suatu organisasi memiliki harapan yang sama untuk mendapatkan yang baik karier (Pawero, 2017). Dengan jenjang karir jadi motivasi karyawan untuk bekerja dalam melaksanakan tugas dan semakin besar tanggung jawab. Selain itu dengan jenjang karir yang diberikan akan mempengaruhi disiplin kerja karyawan(Taghulihi, 2015). Organisasi modern telah berevolusi dari berorientasi produksi menjadi lebih berpusat pada karyawan. Peran sumberdaya manusia dalam organisasi modern telah bergeser dalam hal kegunaan dan pengaruhnya bagi organisasi secara keseluruhan(Chelladurai \& Kerwin, 2018). Dengan demikian, tujuan sumberdaya manusia kemudian berubah dari fungsi yang didominasi peran manajemen sumber daya manusia ke peran yang lebih strategis untuk mengembangkan dan memelihara staf yang berorientasi pada karir yang dinamis.

Kedua, dalam penelitian menggunakan regresi linier sederhana untuk mengetahui pengaruh karir pengembangan kinerja karyawan. Pengujian dapat membuktikan bahwa terdapat pengaruh pengembangan karir terhadap kinerja karyawan. Kinerja karyawan meningkat seiring dengan kualitas pengembangan karir yang lebih baik yang mana salah satu bentuk dukungan organisasi. Ada beberapa alasan mengapa berkarir pengembangan dapat mempengaruhi kinerja karyawan; salah satunya adalah fakta perkembangan karir program, difasilitasi secara efektif oleh organisasi, akan menyebabkan persepsi karyawan tentang tujuan mereka bekerja dan mengapa mereka bekerja keras. Karyawan akan merasakannya dibantu oleh tujuan yang jelas dan realistis pengaruhnya terhadap motivasi mereka untuk 
mengembangkan keterampilan mereka dan pada akhirnya akan berdampak pada prestasi kerja(Nami Nasution et al., 2018).

Penelitian yang ketiga, mendukung temuan penelitian ini adalah menyatakan bahwa motivasi kerja karyawan ditentukan oleh sejauh mana mereka paham terhadap tugas yang diberikan oleh organisasi. Pemahaman diperoleh melalui pembelajran dengan tujuan untuk membantu karyawan mengembangkan potensi yang mereka miliki (Arar \& Öneren, 2018). Dengan kata lain, bahwa hasil belajar yang diperoleh memberikan kontribusi memadai ketika melaksanakan pekerjaannya. Demikian pula halnya sebagaimana yang dikatakan (Eke, 2018) penerapan sumberdaya manusia yang efektif tujuannya untuk mewujudkan perubahan positif tenaga kerja organisasi.

\section{Simpulan}

Berdasar rangkaian penelusuran literatur pengembangan karir dan kinerja karyawan dan dilanjutkan dengan proses pengukuran dan pengujian hipotesis. Maka, hipotesis yang menyatakan bahwa terdapat dampak pengembangan karir terhadap kinerja karyawan di lembaga pendidikan tinggi Islam diterima dan didukung oleh persepsi yang diperoleh dari karyawan sebagai unit analisis. Besaran dampak tersebut adalah sebesar $61.8 \%$. Temuan inipun sejalan dengan penelitianpenelitian yang dilakukan oleh peneliti lain dalam tema sejenis.

Adapun saran untuk penelitian lanjutan, kiranya peneliti yang terlibat dalam tema pengembangan karir dapat mengikutkan variabel-variabel lain yang memiliki kontribusi berarti bagi kinerja karyawan. Sedangkan dalam metode dapat disarankan agar dilakukan pendekatan penelitian dengan mix method dengan tujuan memperkaya upaya pengungkapan tema penelitian.

\section{Referensi}

Abdurakhmanova, G., Shayusupova, N., Irmatova, A., \& Rustamov, D. (2020). The role of the digital economy in the development of the human capital market. Архив Научных Исследований, 25.

Aburumman, O., Salleh, A., Omar, K., \& Abadi, M. (2020). The impact of human resource management practices and career satisfaction on employee's turnover intention. Management Science Letters, 10(3), 641-652. https://doi.org/10.5267/j.msl.2019.9.015

Ahmad, A. (2020). SCHOOL-BASED MANAGEMENT IN DEVELOPING GRADUATE QUALITY. HAKI.

Ahmed, A., Khuwaja, F. M., Brohi, N. A., Othman, I., \& Bin, L. (2018). Organizational factors and organizational performance: A resource-based view and social exchange theory viewpoint. International Journal of Academic Research in 
Business and Social Sciences, 8(3), 579-599.

Alessandri, G., Consiglio, C., Luthans, F., \& Borgogni, L. (2018). Testing a dynamic model of the impact of psychological capital on work engagement and job performance. Career Development International.

Alfes, K., Veld, M., \& Fürstenberg, N. (2020). The relationship between perceived high-performance work systems, combinations of human resource well-being and human resource performance attributions and engagement. Human Resource Management Journal.

Arar, T., \& Öneren, M. (2018). Role of Talent Management in Career Development of Generation Z: A Case Study of a Telecommunication Firm. International Academic Journal of Social Sciences, 05(01), 28-44. https://doi.org/10.9756/iajss/v5i1/1810004

Armstrong, M., \& Taylor, S. (2020). Armstrong's handbook of human resource management practice.

Arsi, A., \& Arsyam, M. (2021). Administrasi Tata Kelola Dalam Pendidikan.

Bafadal, I., Nurabadi, A., Soepriyanto, Y., \& Gunawan, I. (2020). Primary School Principal Performance Measurement. 2nd Early Childhood and Primary Childhood Education (ECPE 2020), 19-23.

Bryson, J. M. (2018). Strategic planning for public and nonprofit organizations: $A$ guide to strengthening and sustaining organizational achievement. John Wiley \& Sons.

Çelik, H. C. (2018). The effects of activity based learning on sixth grade students' achievement and attitudes towards mathematics activities. EURASIA Journal of Mathematics, Science and Technology Education, 14(5), 1963-1977.

Chelladurai, P., \& Kerwin, S. (2018). Human resource management in sport and recreation. Human Kinetics.

Dhamija, P., Gupta, S., \& Bag, S. (2019). Measuring of job satisfaction: the use of quality of work life factors. Benchmarking: An International Journal.

Dobre, O.-I. (2013). Employee motivation and organizational performance. Review of Applied Socio-Economic Research, 5(1).

Eke, G. J. (2018). Contemporary Issues in Employee Motivation and Performance in Organizations. Social Sciences, 5(1).

Espino-Díaz, L., Fernandez-Caminero, G., Hernandez-Lloret, C.-M., GonzalezGonzalez, H., \& Alvarez-Castillo, J.-L. (2020). Analyzing the impact of COVID-19 on education professionals. toward a paradigm shift: ICT and neuroeducation as a binomial of action. Sustainability, 12(14), 5646.

Esthi, R. B., \& Savhira, I. (2019). The Influence of Work Training, Competence and Discipline of Work on Employee Performance in PT. Lestarindo Perkasa. Journal of Research in Business, Economics, and Education, 1(2).

Faggian, A., Modrego, F., \& McCann, P. (2019). Human capital and regional development. In Handbook of regional growth and development theories. 
Edward Elgar Publishing.

Fahim, M. G. A. (2018). Strategic human resource management and public employee retention. Review of Economics and Political Science.

Farikhah, S. (2015). Manajemen lembaga pendidikan. Aswaja Presindo.

Ghozali, I. (2015). Partial Leaast Square, Konsep, Teknik dan Aplikasi Menggunakan Program SmartPLS 3.0. Universitas Diponegoro.

Günay, G. Y. (2018). Relationship between job satisfaction, organizational citizenship behavior and employee performance: Sample of Edirne financial office employees in Turkey. American International Journal of Contemporary Research, 8(1), 64-74.

Han, J., Sun, J.-M., \& Wang, H.-L. (2020). Do high performance work systems generate negative effects? How and when? Human Resource Management Review, 30(2), 100699.

Heilmann, P., Forsten-Astikainen, R., \& Kultalahti, S. (2020). Agile HRM practices of SMEs. Journal of Small Business Management, 58(6), 1291-1306.

Hutahayan, B. (2020). The mediating role of human capital and management accounting information system in the relationship between innovation strategy and internal process performance and the impact on corporate financial performance. Benchmarking: An International Journal.

Idris, S. (2019). International Journal of Social Science and Economic Research THE INFLUENCE OF PARTICIPATIVE LEADERSHIP AND TEAMWORK ON EMPLOYEE JOB SATISFACTION AND ITS IMPACT ON ORGANIZATIONAL PERFORMANCE AT THE UNIVERSITY OF MUHAMMADIYAH ACEH , PROVINCE OF ACEH , INDO. 169(July), 5077-5098.

Jafari-Sadeghi, V., Kimiagari, S., \& Biancone, P. Pietro. (2019). Level of education and knowledge, foresight competency and international entrepreneurship: A study of human capital determinants in the European countries. European Business Review.

Jandrić, P., Jaldemark, J., Hurley, Z., Bartram, B., Matthews, A., Jopling, M., Mañero, J., MacKenzie, A., Irwin, J., \& Rothmüller, N. (2020). Philosophy of education in a new key: Who remembers Greta Thunberg? Education and environment after the coronavirus. Educational Philosophy and Theory, 1-21.

Javaid, J., Soroya, S., \& Mahmood, K. (2020). Impact of personal and organizational factors on knowledge sharing attitude of university teachers in Pakistan. The Electronic Library.

Karman, A. (2020). Understanding sustainable human resource managementorganizational value linkages: The strength of the SHRM system. Human Systems Management, 39(1), 51-68.

Kennington, B. (2020). Managing the affective responses of employees during organizational change in higher education.

Kucharčíková, A., \& Mičiak, M. (2018). The application of human capital efficiency 
management towards the increase of performance and competitiveness in an enterprise operating in the field of distribution logistics. NAŠE MORE: Znanstveni Časopis Za More i Pomorstvo, 65(4 Special issue), 276-283.

Leikin, R. (2020). Giftedness and high ability in mathematics. Encyclopedia of Mathematics Education, 315-325.

Leitão, J., Pereira, D., \& Gonçalves, Â. (2019). Quality of Work Life and Organizational Performance: Workers' Feelings of Contributing, or Not, to the Organization's Productivity. International Journal of Environmental Research and Public Health, 16(20), 3803.

Liu, J., Yuan, C., Hafeez, M., \& Yuan, Q. (2018). The relationship between environment and logistics performance: Evidence from Asian countries. Journal of Cleaner Production, 204, 282-291.

Manggis, I. W., Yuesti, A., \& Sapta, I. K. S. (2018). The Effect of Career Development and Organizational Culture to Employee Performance with Motivation of Work as Intervening Variable in Cooperation in Denpasar Village. International Journal of Contemporary Research and Review, 9(07), 20901-20916. https://doi.org/10.15520/ijcrr/2018/9/07/553

Matraeva, A. D., Rybakova, M. V, Vinichenko, M. V, Oseev, A. A., \& Ljapunova, N. V. (2020). Development of Creativity of Students in Higher Educational Institutions: Assessment of Students and Experts. Universal Journal of Educational Research, 8(1), 8-16.

Mellander, C., \& Florida, R. (2021). The rise of skills: Human capital, the creative class, and regional development. Handbook of Regional Science, 707-719.

Nami Nasution, F., Mariatin, E., \& Zahreni, S. (2018). The Influence of Career Development and Organizational Culture on Employee Performance. International Journal of Scientific Research and Management, 6(01), 57-65. https://doi.org/10.18535/ijsrm/v6i1.elo9

Nourani, M., Chandran, V. G. R., Kweh, Q. L., \& Lu, W.-M. (2018). Measuring human, physical and structural capital efficiency performance of insurance companies. Social Indicators Research, 137(1), 281-315.

Ogbonnaya, C., \& Valizade, D. (2018). High performance work practices, employee outcomes and organizational performance: a 2-1-2 multilevel mediation analysis. The International Journal of Human Resource Management, 29(2), 239259.

Otoo, F. N. K. (2019). Human resource management (HRM) practices and organizational performance. Employee Relations: The International Journal.

Pan, W., Chen, L., \& Zhan, W. (2020). Implications of construction vocational education and training for regional competitiveness: Case study of Singapore and Hong Kong. Journal of Management in Engineering, 36(2), 5019010.

Panagiotakopoulos, A. (2020). Exploring the link between management training and organizational performance in the small business context. Journal of Workplace 
Learning.

Pawero, A. M. V. D. (2017). Analisis Kritis Kebijakan Standar Kompetensi Lulusan (SKL) Dan Standar Isi Kurikulum Pendidikan Agama Islam. Journal of Islamic Education Policy, 2(2), 166.

Polychroniou, P., \& Trivellas, P. (2018). The impact of strong and balanced organizational cultures on firm performance: Assessing moderated effects. International Journal of Quality and Service Sciences.

Prasad, D. K. D. V, Rao, M., Vaidya, D. R., \& Muralidhar, B. (2020). Organizational climate, opportunities, challenges and psychological wellbeing of the remote working employees during COVID-19 pandemic: a general linear model approach with reference to information technology industry in hyderabad. International Journal of Advanced Research in Engineering and Technology (IJARET), 11(4).

Riduwan \& Engkos Ahmad Kuncoro. (2007). Cara Menggunakan dan Memaknai Analisis Jalur (Path Analysis). Alfabeta.

Roszkowska, P., \& Melé, D. (2020). Organizational Factors in the Individual Ethical Behaviour. The Notion of the "Organizational Moral Structure." Humanistic Management Journal, 1-23.

Salama, A. A. M., Abu Amuna, Y. M., Al Shobaki, M. J., \& Abu-Naser, S. S. (2018). The Role of Administrative Procedures and Regulations in Enhancing the Performance of The Educational Institutions-The Islamic University in Gaza is A Model.

Sapada, A. F. A., Modding, H. B., Gani, A., \& Nujum, S. (2018). The effect of organizational culture and work ethics on job satisfaction and employees performance.

Soomro, B. A., Mangi, S., \& Shah, N. (2020). Strategic factors and significance of organizational innovation and organizational learning in organizational performance. European Journal of Innovation Management.

Stahl, G. K., Brewster, C. J., Collings, D. G., \& Hajro, A. (2020). Enhancing the role of human resource management in corporate sustainability and social responsibility: A multi-stakeholder, multidimensional approach to HRM. Human Resource Management Review, 30(3), 100708.

Sudiardhita, I. K. R., Dianta, K., Susita, D., \& Aisyah, N. (2019). Placement , Career Development on Employee Performance With Job Satisfaction as Intervening Variables. DLSU Business \& Economics Review, 28(3), 73-80.

Swanson, E., Kim, S., Lee, S.-M., Yang, J.-J., \& Lee, Y.-K. (2020). The effect of leader competencies on knowledge sharing and job performance: Social capital theory. Journal of Hospitality and Tourism Management, 42, 88-96.

Taghulihi, I. A. (2015). The Effect Of Motivation, Career Development, And Work Discipline On Employee Performance at PT . Bank Sulutgo In Tagulandang. Journal Berkala Ilmiah Efisiensi, 15(05), 925-930.

Washington, E. (2020). Human resource management and organizational behavior, 
Competencies at work providing a common language for talent management. Business Expert.

Wyatt-Elkins, P. J. (2020). Using Human Capital Development to Reduce Healthcare Administrative Costs.

Yasin, A. F. (2011). Pengembangan Sumber Daya Manusia di Lembaga Pendidikan Islam. UIN-Maliki Press.

Yusliza, M. Y., Yong, J. Y., Tanveer, M. I., Ramayah, T., Faezah, J. N., \& Muhammad, Z. (2020). A structural model of the impact of green intellectual capital on sustainable performance. Journal of Cleaner Production, 249, 119334.

Zhang, X., Lin, Z., Liu, Y., Chen, X., \& Liu, D. M. (2020). How do human resource management practices affect employee well-being? A mediated moderation model. Employee Relations: The International Journal. 